\title{
YIELD MAPPING IN PRECISION FARMING
}

\author{
M. Zhang, M.Z. Li , G. Liu, M.H. Wang \\ Key Laboratory of Modern Precision Agriculture System Integration Research, China \\ Agricultural University, Ministry of Education, Beijing 100083, China
}

\begin{abstract}
Spatial variability of yield is very important in precision farming. With a yield monitor system installed on combine harvester, the yield data can be collected automatically while harvesting. In this paper, the component and the working theory of the yield monitor system were introduced. Performance of main sensors and the method improving GPS position accuracy were analyzed. Based on the analysis, a new grain yield monitor is developed and performance tested. The crop harvested was wheat, and the harvesting combine used to equip the monitor was JL1603, a typical machine in northern China with $4 \mathrm{~m}$ of header width. And. The yield map was created to support decision making in precision agriculture.
\end{abstract}

Keywords: $\quad$ precision agriculture, yield monitor system, grain flow sensor, yield map

\section{INTRODUCTION}

In practice of precision agriculture, most important thing is to realize the spatial and temporal variability of the field conditions, yield, soil fertilizer, crop growing status, and so on. Then, it is needed to analyze the reason influence crop growing according to above information. And finally, it is necessary to input fertilizer, pesticide etc based on the crop demand.

A yield map is the basis for understanding the yield variability within a field, analyzing reasons behind the yield variability, and improving management according to the increase of the profit (M.H. Wang, 1999). So a yield monitors system need to be installed on combine harvester, and the yield data can be recorded automatically while harvesting (L. Thylen, 1996).

Zhang, M., Li, M.Z., Liu, G. and Wang, M.H., 2008, in IFIP International Federation for Information Processing, Volume 259; Computer and Computing Technologies in Agriculture, Vol. 2; Daoliang Li; (Boston: Springer), pp. 1407-1410. 


\section{THE DEVELOPMENT OF INTELLIGENT CONTROLLER}

\subsection{Development of Hardware}

The intelligent controller collected four analog signals (grain flow, header height, grain moisture, and grain temperature), two pulse signals (ground speed and elevator speed), and DGPS data. After a series of process, the system stored all data on a CompactFlash ${ }^{\circledR}(\mathrm{CF})$ card once per second. The yield monitor also included a liquid crystal display (LCD) and a touch screen as the Man-Machine interface. Figure 1 shows the diagram of the intelligent controller developed. It uses a P80C592 manufactured by Philips Semiconductors as the microcontroller.

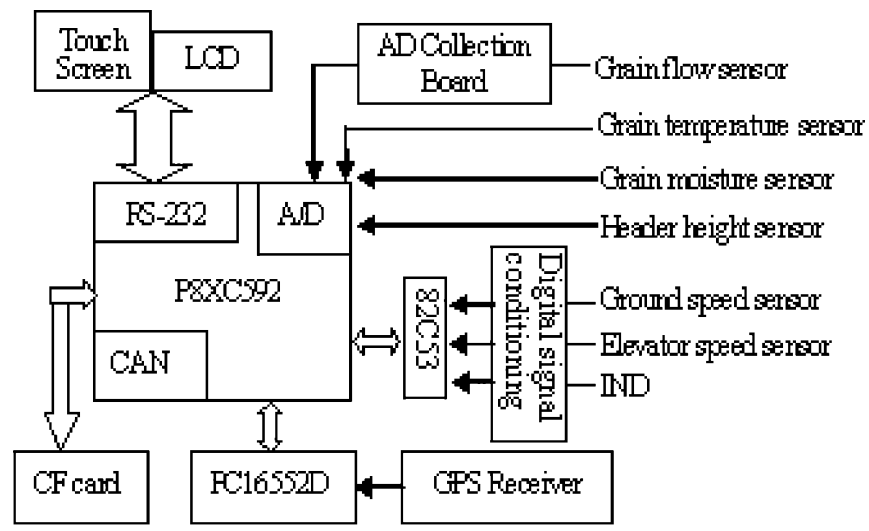

Figure 1. Diagram of the intelligent controller developed

Pretests showed that a sampling frequency of at least $200 \mathrm{~Hz}$ was needed for the system to properly record the impaction on the flow sensor. However, it was hard to increase the sampling frequency on the main microcontroller since its load had been heavy enough. Therefore, a new signal acquisition circuit board was specially designed to collect grain flow signals with a frequency of $250 \mathrm{~Hz}$. After sampling, the board calculated the mean of 250 data obtained in one second, and then sent the result to the main microcontroller.

\subsection{Programming of Software}

There are five tasks to be dealt with by the program; they are data acquisition, data processing, LCD displaying, touch screen input, and data saving. The details of them are shown in Figure 2. 


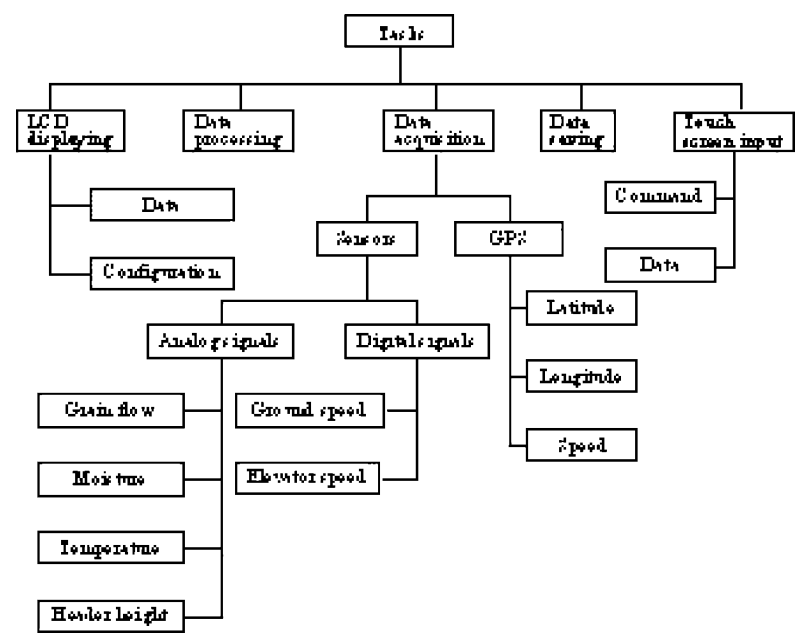

Figure 2. Tasks of the program

These tasks make up a multitasking real time system. However, it may results in some conflicts of the tasks in time sequence. So four interrupt sources of P80C592 are used in the system, which are the timer interrupt source, the external interrupt source, the ADC end-of-conversion interrupt source and the UART serial I/O port interrupt source.

\section{FIELD TRIAL}

The system was installed on the combine harvester and began to harvest wheat on June 11, 2004. And the harvesting combine used to equip the monitor was JL1603, with $4 \mathrm{~m}$ of header width. Before harvest, the yield monitor system was setup. In order to reduce the systematic error, before harvesting a whole field, the system was calibrated in a smaller area in the similar condition with the whole field. After harvest, the data that collected by the yield monitor system were output and be analyzed by some software. The winter wheat yield map of the field F1 generated after the error yield data processing is shown in Figure 3. The maps were generated using Surfer6 via IDW (Inverse Distance Weighted) interpolation. The output grid size is $20 \mathrm{~m}$, and search radius is $20 \mathrm{~m}$. In this map, yield decreased with color. The yield around the field was lower than the center. According to this yield map, understanding the yield variability within a field, analyzing reasons behind the yield variability, improving management, then the profit can be increased. 


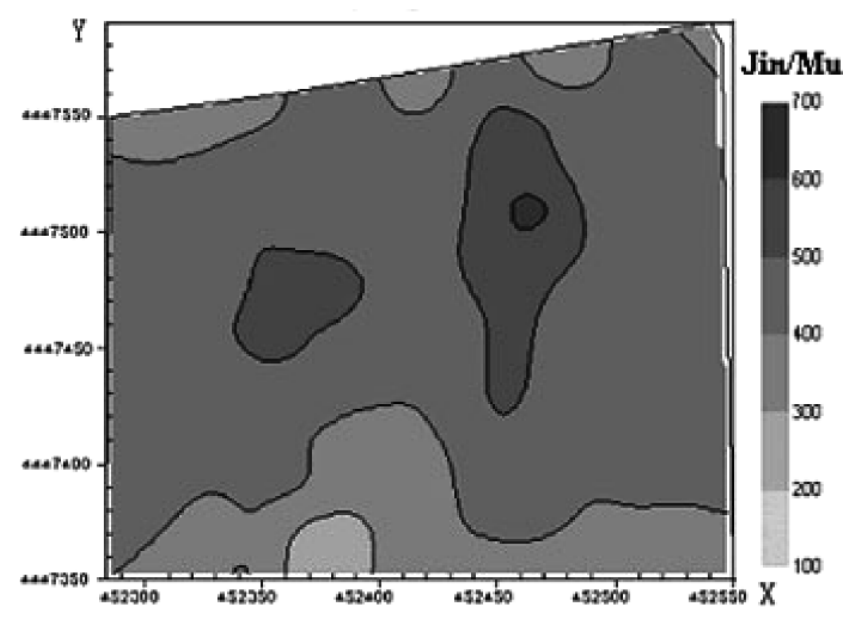

Figure 3. Yield map of field F1

\section{CONCLUSION}

This paper introduced components and the working theory of yield monitor system; compared the performance of main sensors and the method of improving GPS position accuracy. Then, a grain intelligent controller based on an 8-bit microcontroller was developed, and the programming of the software used for the monitor was conducted. A long time of laboratory and field tests showed that the whole worked steadily. However, the capability of handling multitask should be optimized. Finally, grain yield map was created. According to this map, to analyze the reason that caused the yield variability within a field, further to improve crop management and decrease input.

\section{ACKNOWLEDGEMENTS}

This study was supported by National 863 Program (2006AA10A305).

\section{REFERENCES}

L. Thylen and Donal P.L. Murphy, The Control of Errors in Momentary Yield Data from Combine Harvesters, Journal of Agriculture Engineering Research, 1996, 64: pp. 271-278

M.H. Wang, Field Information Collection and Process Technology. Agriculture Mechanization [J], 1999, Vol. 7, pp. 22-24 